\title{
A Comparative Study on the Properties of Natural, Synthetic and Steel Fibre Reinforced Concrete
}

\author{
Ashadul Islam*, Aojoy Kumar Shuvo, Showaib Ahmed Chowdhury, Shayla Sharmin, Mehedi \\ Hasan \\ Department of Building Engineering \& Construction Management, Rajshahi University of Engineering \& \\ Technology, Rajshahi-6204, Bangladesh \\ E-mail: asadruetce11@gmail.com (Corresponding Author)
}

Received: 28 April 2021; Accepted: 5 July 2021; Available online: 20 August 2021

\begin{abstract}
The use of fibers in concrete at relatively low volume fraction has been gaining rising popularity among researchers for the recent years due to its availability, ability to enhance overall performance and cost effectiveness. Fibers are mainly classified according to their origin. Numerous researches have been carried out with natural and artificial fibers separately to elucidate its effect on the various parameters of concrete. However, a little finding is available about the comparative study among these three distinct types of fibers affecting concrete properties. In this study coconut coir, nylon thread and low-cost galvanized iron wire have been selected as natural, synthetic and steel fibers respectively. Coconut coir and nylon thread were mixed at three different percentage of $1.5 \%$, $2.5 \%$ and $3.5 \%$ respectively by weight of cement. Steel fibre contents $1.5 \%, 2.5 \%$ and $3.5 \%$ respectively by weight of concrete. The results were obtained through an experimental investigation that shows the influence of natural, synthetic and steel fibers on rheological and mechanical properties of concrete. Optimum fibre content was 2.5\% where steel fibre shows a maximum $17 \%$ and $30 \%$ rise in compressive and flexure strength respectively. On the other hand, fibres play a great role with its combining effect on the post cracking ductility and energy absorption of concrete.
\end{abstract}

Keywords: Fibre reinforced concrete; Fibre content; Slump value; Mechanical properties; Failure characteristics.

\section{Introduction}

In the present world the infrastructure development largely depend on the use and enhancing of the properties of concrete. One such improvement is the incorporation of fibres to overcome the weakness of concrete such as brittleness, weak in tension, cracking etc. Use of suitable amount of fibres also increases strength, ductility, elastic modulus and serviceability of concrete members. Many researches have been carried out with various types of fibres. The potentiality of coconut stem, coconut fibre, coconut and coconut fibre ash, banana fibre bars, steel fibre, crumb rubber and steel fibres, waste tires rubber and recycled aggregate, FRP rebar and steel fibre, polypropylene hybrid fibre to enhance the strength characteristics of concrete, was elaborately investigated and satisfactory result was found [1-11]. A research work to evaluate the effectiveness of banana fibre to promote the impact strength lightweight self-compacting concrete executed that $1.25 \%$ addition of banana fibres could improve the impact strength of lightweight self-compacting concrete with no undesirable effect on the self-compatibility [12]. A case study to enhance the quality of concrete, utilizing locally available low-cost Galvanized Iron (GI) wire fibres in concrete suggested that 2.5-3.5\% of Galvanized Iron (GI) wire fibres by weight could produce relatively better results for a particular mix design [13]. Use of fibre in concrete also improves permeability properties. Investigation shows that, up to 75\% replacement of coarse aggregate with coconut shell aggregate in light weight self-consolidating concrete exhibited better results with respect to permeability properties [14]. Addition of basalt fibre on volumetric dosage had influences on flexural performance. Research suggests that $0.2-0.25 \%$ of basalt fibre dosage improve the structural strength [15]. In an experiment, the addition of lathe factories waste fibres to recycled concrete geopolymer beams confirmed better results to improve the displacement ductility, energy absorption, loading carrying capacity and toughness [16]. The influence of polyethylene terephthalate waste fibres on the strengths and serviceability of reinforced concrete beams and there was found remarkable progress in ductility and stiffness behavior [17]. Another research work observed the mechanical behavior of Carbon NanoFiber (CNF) Composites, and Hybrid-Fibre Composites. For 0.025\% inclusion of CNFs caused the improvement of $40 \%$ in flexural strength, $45 \%$ in tensile strength, and $85 \%$ in toughness [18]. Fibres not only used in the concrete but also improve the property of soil cement mortar [19-20]. 
A wide range of materials which have the reinforcing action can be mixed with concrete to improve its physical and mechanical properties. The fibres which are locally available and obtained from natural sources can be a sustainable alternative and low cost solution. Most of the previous works in literature are conducted on single or at most considering two types of fibre. However, a little number of researches is found where three basic types of fibres have been considered with similar fibre content. In this study, the prime focus was to evaluate and compare the utility of coconut coir, nylon fiber and galvanized iron wire mixed with same mix proportioned concrete. On the basis of the flexural, compressive strength, cracking pattern and mechanical interaction of the fibers with concrete materials, the performances of the concrete composited with three different fibers were justified.

\section{Materials}

Ordinary Portland cement (OPC) was used in this study which is the most commonly utilized cement type for general engineering works in Bangladesh. The Chemical compositions of cement are given in Table 1. Natural crushed stone $20 \mathrm{~mm}$ downgrade was used as coarse aggregate. Locally available natural river sand having maximum size of $4.75 \mathrm{~mm}$ was used as fine aggregate collected from Rajshahi, Bangladesh. To remove the organic matters the sample of fine aggregate was cleaned according to ASTM C33/C33M-18 standard [21]. The physical properties of coarse and fine aggregate are listed in Table 2.

Table 1. Chemical compositions of cement.

\begin{tabular}{ll}
\hline Constituents & Weight (\%) \\
\hline Silica $\left(\mathrm{SiO}_{2}\right)$ & 20.76 \\
Alumina $\left(\mathrm{Al}_{2} \mathrm{O}_{3}\right)$ & 4.76 \\
Ferric Oxide $\left(\mathrm{Fe}_{2} \mathrm{O}_{3}\right)$ & 3.32 \\
Calcium Oxide $(\mathrm{CaO})$ & 65.12 \\
Magnesium Oxide $(\mathrm{MgO})$ & 1.20 \\
Sulfur trioxide $\left(\mathrm{SO}_{3}\right)$ & 2.23 \\
Insoluble Residue $(\mathrm{IR})$ & 0.36 \\
Free Lime & 0.94 \\
Loss of Ignition $(\mathrm{LOI})$ & 0.52 \\
Ratio of $\mathrm{Al}_{2} \mathrm{O}_{3}$ to $\mathrm{Fe}_{2} \mathrm{O}_{3}$ & 1.43 \\
\hline
\end{tabular}

Table 2. Physical properties of aggregate.

\begin{tabular}{lll}
\hline Parameters & Coarse Aggregate & Fine Aggregate \\
\hline Fineness modulus & 6.12 & 2.96 \\
Specific gravity & 2.69 & 2.89 \\
Moisture content & $20.3 \%$ & $14.5 \%$ \\
\hline
\end{tabular}

Coconut coir was used in the study as natural fibre obtained from the nature. The coir sample was kept immerged in water 24 hour to remove all undesirable matters and impurities. Then the moist coconut fibres were dried under sunlight more than 5 hours. Nylon thread was used as synthetic fibre collected from nearby market. According to ACI 544.3R steel fibre length varies from $12.7 \mathrm{~mm}$ to $63.5 \mathrm{~mm}$ to be used in fibre reinforced concrete (FRC) and diameter of fibre varies mostly from $0.45 \mathrm{~mm}$ to $1.0 \mathrm{~mm}$ [22]. The aspect ratio is defined as the ration of length $(\ell)$ and diameter $(d)$ or the equivalent diameter $\left(\mathrm{d}_{\mathrm{e}}\right)$ in certain cases. The code specifies that the value of aspect ratio should lie between 30 and 100. The above specifications for steel fible also comply with the ASTM-A 820/A 820 M standard [23]. Table 3. shows the physical properties of natural, synthetic and steel fibres. Visual representation and corresponding length scale of coconut coir, nylon and steel fibres are shown in Fig. 1. Fresh potable water conforming the drinking standard ASTM C1602/C1602M-18 was used in mixing all types of concrete [24].

Table 3. Physical properties of natural, synthetic and steel fibres.

\begin{tabular}{llll}
\hline Properties & Natural fibre (Coir) & Synthetic fibre & Steel fibre \\
\hline Length (mm) & $45-55$ & $45-55$ & $45-55$ \\
Diameter (mm) & 0.6 & 0.7 & 0.7 \\
Aspect Ratio & $75-91$ & $64-78$ & $64-78$ \\
\hline
\end{tabular}




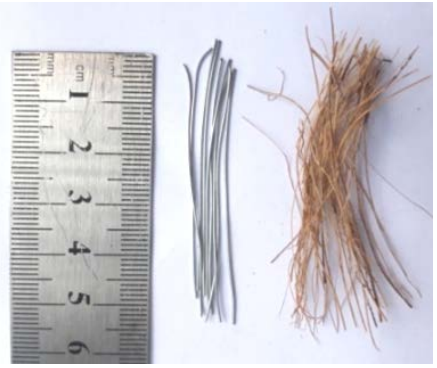

Fig. 1. Sample of fibre

\section{Experimental investigations}

\subsection{Mix proportion and casting of concrete}

Concrete mix ratio of 1: 1.5: 3 by weight of cement, fine aggregate and coarse aggregate were used for mixing the concrete. The reason for using this proportion is that most of the concrete works in Bangladesh are done using this mix ratio. Water cement ration of 0.50 was chosen for all types of concrete mix and no water reducing admixtures was used in concrete. However, in some cases concrete mixed with fibres losses workability which is very common for FRC may be needed use of admixtures [25]. Natural and synthetic fibres were added at three different percentage of $1.5 \%, 2.5 \%$ and $3.5 \%$ respectively by weight of cement. On the other contrary, steel fibre contents $1.5 \%, 2.5 \%$ and $3.5 \%$ respectively by weight of concrete. Four types of concrete mixes were prepared in the present study where the first category contains no fibre called control specimen and rest of the specimen contains $1.5 \%, 2.5 \%$ and $3.5 \%$ of natural, synthetic and steel fibres respectively. The whole operation of concrete mixing and curing was performed according to ASTM C192/C192M - 19 [26]. Fibres were mixed gradually in three consecutive times so as to get a homogeneous mixture of FRC.

\subsection{Test on fresh concrete}

The workability of concrete was measured on fresh concrete. Workability of concrete indicates the relative ease with which concrete can be placed, compacted and finished without segregation. Slump test is the most common and widely used method of measuring workability of concrete. The workability and consistency of fresh concrete was determined by slump test according to ASTM C143 [27]. Slump test on control and FRC concrete explains the effect of incorporating fibres on concrete workability. Fig. 2 shows clearly the arrangement of slump test and measurement of slump value.
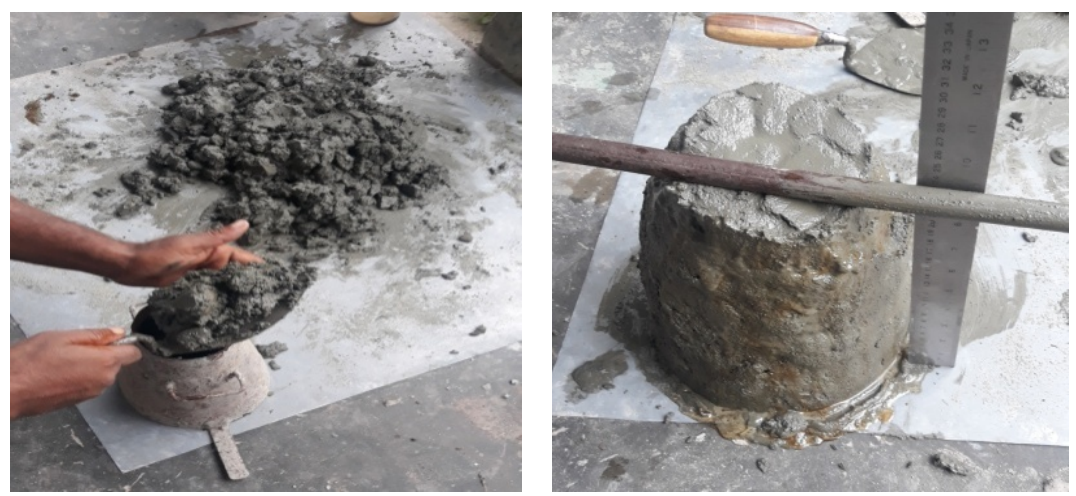

Fig. 2. Slump test (a) mould preparation (b) slump value measurement

\subsection{Test on hardened concrete}

Cube specimens of $150 \mathrm{~mm} \times 150 \mathrm{~mm} \times 150 \mathrm{~mm}$ were prepared for control as well as natural, synthetic and steel fibre reinforced concrete having three different percentage of fibre content. The compressive strength of concrete was measured by universal compression testing machine after 7 days and 28 days of curing respectively.

Load was applied at a constant rate until failure occurred. The compressive strength of concrete was measured by the following expression:

$$
\mathrm{F}=\mathrm{P} / \mathrm{A}\left(\mathrm{N} / \mathrm{mm}^{2}\right)
$$

where, $\mathrm{P}=$ Ultimate load $(\mathrm{N})$ and $\mathrm{A}=$ Loaded area $(150 \mathrm{~mm} \times 150 \mathrm{~mm})$. 
For the determination of flexural strength FRC beams of $100 \mathrm{~mm} \times 100 \mathrm{~mm} \times 450 \mathrm{~mm}$ were prepared and tested under centre point loading according to ASTM C293/C293M - 16 [28]. The flexural strength is expressed as modulus of rupture, $\mathrm{R}$ and is calculated by the following formula:

$$
\mathrm{R}=3 \mathrm{PL} / 2 \mathrm{bd}^{2}\left(\mathrm{~N} / \mathrm{mm}^{2}\right)
$$

where, $\mathrm{P}=$ maximum applied load indicated by the testing machine $(\mathrm{N})$; $\mathrm{L}=$ span length $(\mathrm{mm})$; $\mathrm{b}=$ average width of specimen, at the fracture $(\mathrm{mm})$ and $\mathrm{d}=$ average depth of specimen, at the fracture $(\mathrm{mm})$.

\section{Results and discussion}

\subsection{Effect of fibre content on slump value}

Slump values for zero and three different percentage of fibre content are shown in Fig. 3. It is clear from the graphical representation that the maximum slump value is $52 \mathrm{~mm}$ for control specimen when no fibre was mixed with the concrete. With the addition of fibre in concrete the value of slump decreases significantly for all three types of fibres. The more is the percentage of fibre in concrete less is the slump value of concrete. The reason for the reduction of slump value can be explained from the concept of concrete technology. The less is the size of the aggregate, the greater is the surface area and hence higher amount of water is required for wetting the surface of aggregate. Therefore, for a given amount of water smaller size of aggregate will give less workability. Similarly, mixing of fibres in concrete increases the surface area contributing from the fibres in addition of aggregate surface. The mortar must coat the surface of fibres and high amount of paste is required for wetting the surface of aggregate as well as fibres. So, for a given amount of water slump value shows a decreasing trend when the amount of fibre increased in the concrete mix. Another reason may be the formation of three-dimensional scaffolding inside the concrete mix by the intertwined array of fibres. The scaffolding is weak when the fibre content is less and strong enough for a higher percentage of fibre content [13]. Among the three types of fibre mixed concrete the lowest slump value is observed when coconut coir fibre is added to the concrete. For $3.5 \%$ fibre content the slump value is zero. One reason for the high reduction of slump value is the absorption of water by the coir fibre from the mix. Steel and synthetic fibre concrete represents almost same pattern of slump value.

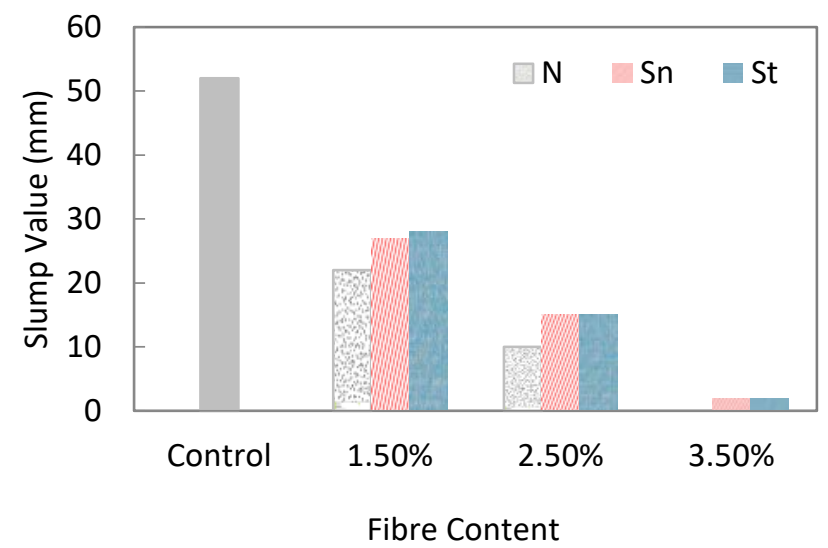

Fig. 3. Slump values of control and FRC sample

\subsection{Effect of fibre content on compressive strength}

All specimens for each concrete mix were prepared and tested after 7 days and 28 days curing period. Fig. 4 illustrates the variation of compressive strength for three different percentage of natural, synthetic and steel fibre reinforced concrete. After 7 days the maximum compressive strength for normal concrete is $18 \mathrm{MPa}$. In case of natural fibre mixed concrete, the strength ranges from 16-17 $\mathrm{MPa}$. On the other hand, the maximum compressive strength when the concrete is mixed with steel and synthetic fibre is $18 \mathrm{MPa}$ and $15 \mathrm{MPa}$ respectively. In all the cases 7 days strength follows a decreasing trend when concrete is mixed with fibres. This is due to the fact that at the very early stage the bond among the constituents of concrete such as coarse aggregate, fibres and cement matrix remains weak and hybrid fibre components makes a separation between aggregate and cement paste. Therefore, it can be concluded that fibre possesses no positive influence on compressive strength at early age.

Fig. 5 shows the change in compressive strength for natural synthetic and steel fibre reinforced concrete with respect to normal concrete. The maximum reduction (22\%) in compressive strength occurs for synthetic fibre. One of the reasons for this reduction is due to the low shear modulus of synthetic fibres. Synthetic fibre concrete cannot afford high shear modulus which is required in resisting shearing failure mechanism under compression. 


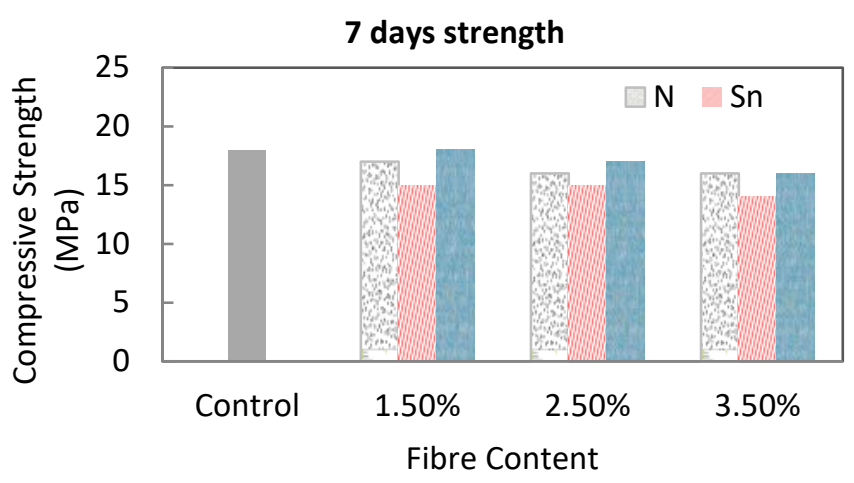

Fig. 4. Compressive strength at 7 days

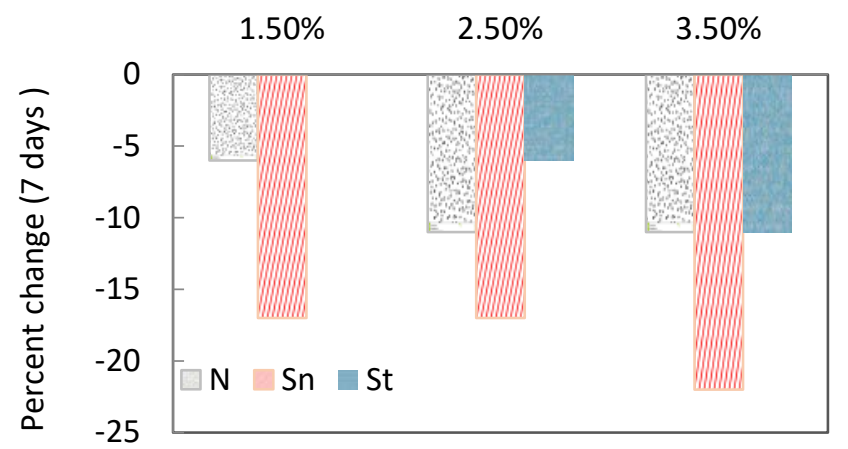

Fig. 5. Percent change in compressive strength at 7 days

Fibre concrete shows a slight increase in compressive strength at later age. From Fig. 6 it is noticeable that steel and natural fibre concrete shows a variable increment in compressive strength at 28 days as compared to the normal concrete. The only different trend is observed for synthetic fibre.

Fig. 7 depicts that compressive strength increased maximum 17\% for steel fibre as compared to control specimen with 2.5\% fibre content. Natural fibre concrete also shows similar behavior, but the increment was not as high as steel fibre concrete. Unlike steel and natural fibre synthetic fibre concrete shows reduction in compressive strength also at later stage which is presented in Fig. 7. The reason for this reduction has already been explained in the previous discussion.

One of the most noticeable differences between the normal concrete and the fibre reinforced concrete was the failure characteristics. As already mentioned, that fibres possesses slight effect on the gain in compressive strength of concrete but they can improve the post cracking ductility and energy absorption of concrete. The combining effect of fibre resist the abrupt crushing of concrete and decrease the amount of lateral strain. From Fig. 8 it is observed that normal concrete fails by breaking of coarse aggregate as well as cement paste. On the other hand, although initial crack develops in the fibre reinforced concrete early but it inhibits failure by crushing. Multiple cracks were developed on the surface of the test specimens containing fibres in different proportion.

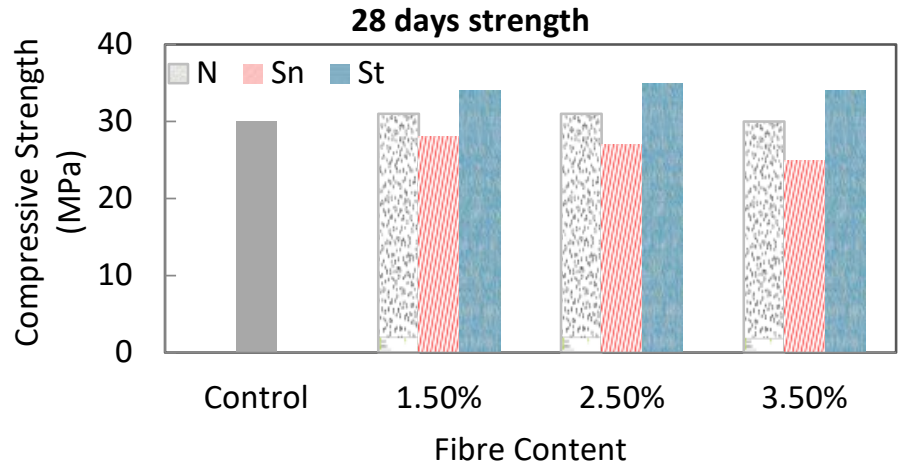

Fig. 6. Compressive strength at 28 days 


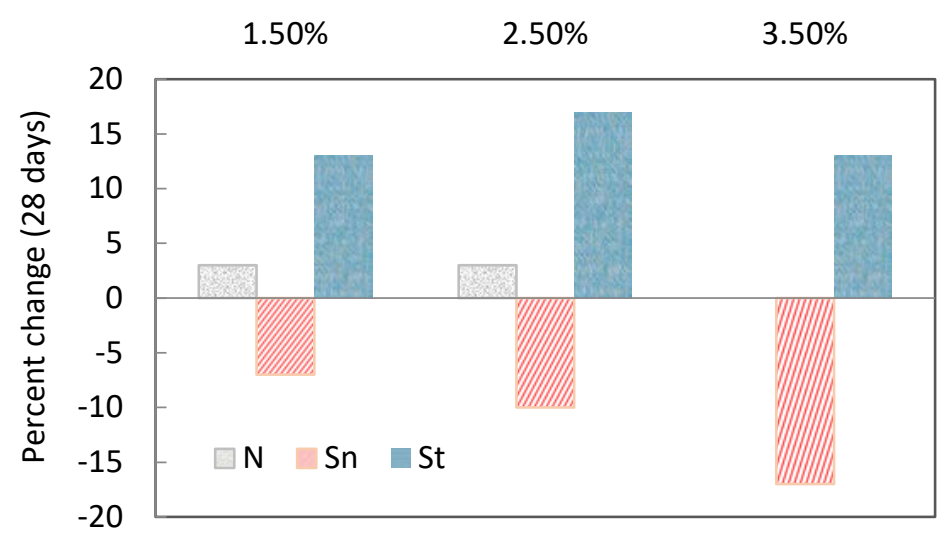

Fig. 7. Percent change in compressive strength at 28 days

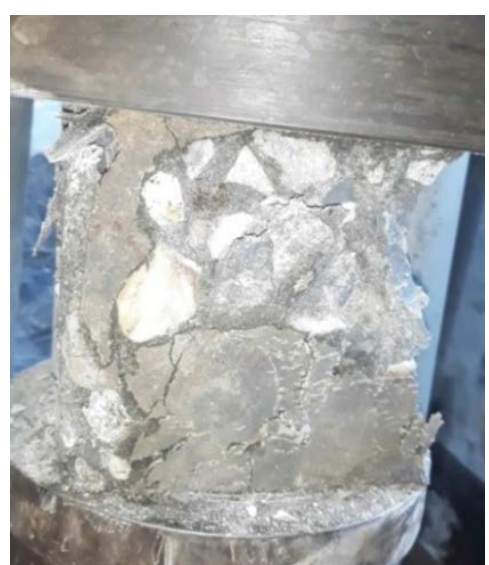

(a)

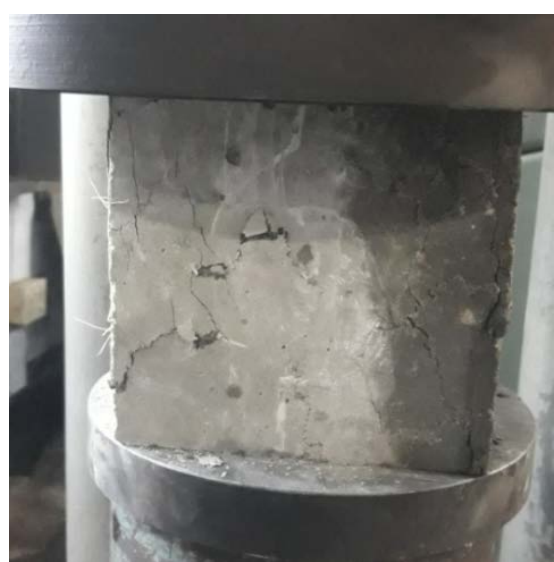

(b)

Fig. 8. Failure pattern (a) normal concrete (b) fibre reinforced concrete

\subsection{Effect of fibre content on flexural strength}

All beam specimens were tested after 28 days curing according to ASTM C293/C293M - 16. Test results of flexural strength are shown in Fig. 9. For control specimen the maximum flexural strength was 6.25 MPa. Unlike compressive strength addition of fibres in concrete increases the flexural strength. From Fig. 9 it is observed that three types of fibre concrete exhibits variable increment in flexural strength for different fibre content. It is clear that steel fibre is more significant in imparting strength than other two types of fibres. Coconut coir has moderate and synthetic fibre has lowest effect in yielding flexural strength of fibre concrete. Fig. 10 shows that natural fibre increase about $10 \%$ and in case of synthetic fibre only $2.5 \%$ addition of fibre uprising the flexural strength to about $10 \%$ as compared to the normal concrete. On the contrary, mixing of steel fibre increases the strength more than $30 \%$ in all three types of fibre content.

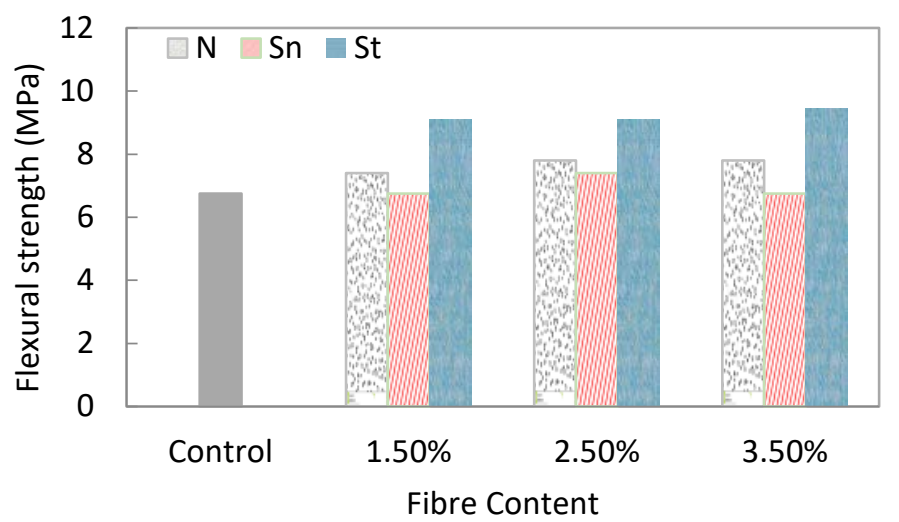

Fig. 9. Flexural strength 


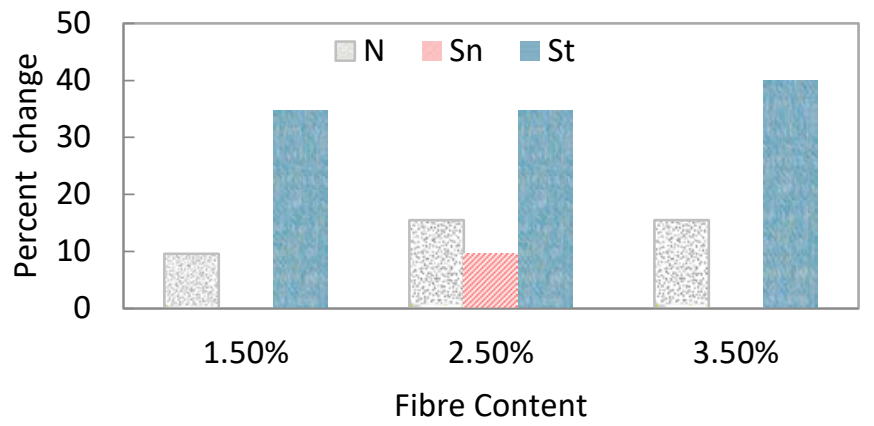

Fig. 10. Percent change in flexural strength

The typical failure pattern of sample beam under flexure is shown in Fig. 11. Control specimen is characterized by brittle failure. It was broken instantly just after reaching ultimate load and snapped into two pieces. There was no forecast in advance before failure. A sudden drop of load was happened when the first crack was developed on the control specimens. Whereas, the fibre concrete carry load even after the crack is observed at ultimate load. The second picture of Fig. 11 displays how fibres make bridge across the crack and resists the crack expansion. This function of fibre makes the concrete more ductile and FRC withstand more strength than the normal concrete. Steel fibre exhibits more ductile behavior than other types of fibres. The optimum fibre content was investigated $2.5 \%$ and also $3.5 \%$ in case of steel fibre. Further study with higher percentage of fibre content may be necessary to clearly investigate whether higher percentage of fibre offers more ductile behavior. But an assumption may be drawn from the present study. As addition of high percentage of fibre decrease workability it implies that lower performance of concrete with respect to ductility, crack resistance and strength capacity will happen.
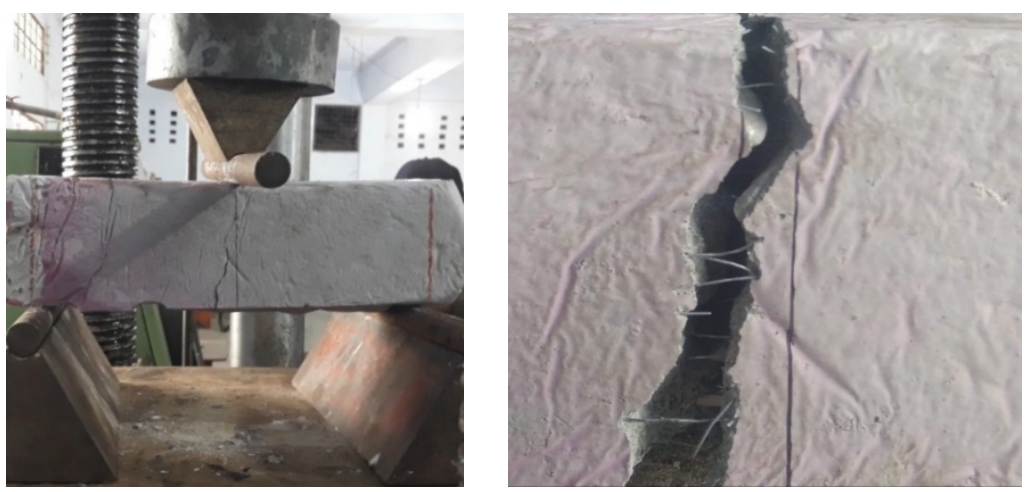

Fig. 11. Beam failure and fibre bridging

\subsection{Relation between test results and code of practice}

The relation between 28 days compressive strength and flexural strength test results and analytical findings from empirical equations suggested by code of practice are shown in the Table 4 . There are various standards that prognosticate the flexural strength from both the cube and cylindrical compressive strength. Equation (1) and (2) are recommended by IS: 456-2000 (India) and EC-02 (Europe) that predict flexural strength from cube compressive strength.

$$
\begin{aligned}
& f_{r}=0.7 \sqrt{f_{c}} \\
& f_{r}=0.201 f_{c}
\end{aligned}
$$

where, $f_{\mathrm{r}}=$ modulus of rupture (flexural strength) at 28 days in $\mathrm{N} / \mathrm{mm} 2$ or MPa and $f_{\mathrm{c}}=$ cube compressive strength at 28 days in $\mathrm{N} / \mathrm{mm} 2$ or MPa.

From table below it is visualized that the test results are very close to EC-02 than IS: 456-2000 particularly in case of control specimen. The reason is that the reference two codes are suggested for normal concrete. Whereas for fibre reinforced concrete the test results are much higher than the analytical calculations. As EC-02 is closer to the experimental result so we are concluding the summary considering this standard. For normal concrete the difference between test and analytical result is $0.72 \mathrm{MPa}$ but for steel fibre reinforced concrete the difference is 2.32 MPa. The difference for normal concrete is very small because they are identical in composition but for steel fibre reinforced concrete this difference is significant that clearly indicate the effect of incorporating fibre in 
concrete. For other two types of fibre concrete the difference is lower than steel which also prove the results that are previously discussed.

Table 4. Comparative performance of test results with respect to code of practice

\begin{tabular}{lcll}
\hline Fibre Type & $\mathrm{f}_{c,(\text { Avr. })}(\mathrm{MPa})$ & Standard & $\mathrm{f}_{r}(\mathrm{MPa})$ \\
\hline Natural & 30.67 & Experiment & 7.67 \\
& & IS: 456-2000 & 3.88 \\
\multirow{3}{*}{ Synthetic } & \multirow{3}{*}{26.67} & EC-02 & 6.16 \\
& & Experiment & 6.97 \\
\multirow{3}{*}{ Steel } & \multirow{3}{*}{34.33} & IS: 456-2000 & 3.62 \\
& & EC-02 & 5.36 \\
& & Experiment & 9.22 \\
Control & \multirow{3}{*}{30} & IS: 456-2000 & 4.10 \\
& & EC-02 & 6.90 \\
& & Experiment & 6.75 \\
& & IS: 456-2000 & 3.83 \\
& & EC-02 & 6.03 \\
\hline
\end{tabular}

\section{Conclusions}

Mixing of different types of fibres in concrete is not a new technique but comparative study among three main types of fibres is very little. This study carried an experimental investigation to determine the rheological and mechanical properties and failure characteristics of normal, natural, synthetic and steel fibre reinforced concrete. The following conclusions can be drawn from the test results and discussion:

1) Addition of fibres in concrete decreases the slump value significantly. When the fibre content is $3.5 \%$ the slump value is nearly zero. So, when the fibre content is high it might be necessary to use certain workability improving agents.

2) Incorporation of fibres in concrete has very little effect on the static compressive strength. The compressive strength at 7 days in case of almost three types of fibres shows a decreasing trend because of weak bond among the constituents of concrete such as coarse aggregate, fibres and cement matrix remains weak and hybrid fibre components makes a separation between aggregate and cement paste. On the contrary, at 28 days of concrete natural and steel fibre showed a slight increase in compressive strength where a maximum $17 \%$ rise is observed when $2.5 \%$ steel fibre was added in concrete.

3) Fibres play a significant role in flexural strength. Three types of fibre concrete impart variable increment in flexural strength for different fibre content. Steel fibre provides significant increase flexural strength which is more than $30 \%$ than the normal concrete. Coconut coir gives moderate and nylon thread small increase when added in concrete.

4) Fibres enhance energy absorption capacity of concrete and provide post cracking ductility. It prevents abrupt crushing during failure and carry load even after the first crack is observed at ultimate load.

5) The three types of fibre and their percentage in concrete plays different role on the rheological and mechanical properties of concrete. For all three types of fibre optimum percentage of fibre was $2.5 \%$ in the study considering the sufficient improve of all properties. Steel fibre shows maximum efficiency in enhancing compressive and flexural strength and also imparts higher ductility. The effect of synthetic fibre in concrete is relatively low due to its low shear modulus especially in compression. The role of natural fibre is very low in improving compressive strength but have moderate effect when subjected under flexure.

\section{References}

[1] Olatokunbo O, Olowofoyeku A, Adaramaja G, Oluwafemi J, Sunday E. Potential use of coconut stem as reinforcement in concrete slab. Case Studies in Construction Materials. 2020;13:e00355. doi.org/10.1016/j.cscm.2020.e00355.

[2] Ali M, Liu A, Sou H, Chouw N. Mechanical and dynamic properties of coconut fibre reinforced concrete. Construction and Building Materials. 2012; 30: 814-825.

[3] Kumar GBR, Kesavan V. Study of structural properties evaluation on coconut fiber ash mixed Concrete. Materials Today: Proceedings. 2019. doi.org/10.1016/j.matpr.2019.10.158.

[4] Elbehiry A, Elnawawy O, Kassem M, Zaher A, Uddin N, Mostafa M. Performance of concrete beams reinforced using banana fiber bars. Case Studies in Construction Materials. 2020;13: e00361. DOI: 10.1016/j.cscm.2020.e00361. 
[5] Suda VBR, Rao PS. Experimental studies on steel fiber reinforced short ternary columns under axial loading. Materials Today: Proceedings. 2020. doi.org/10.1016/j.matpr.2020.09.319.

[6] Yoo DY, Moon DY. Effect of steel fibers on the flexural behavior of RC beams with very low reinforcement ratios. Construction and Building Materials. 2018; 188: 237-254.

[7] Warudkar A, Elavenil DS. Flexural strength of concrete using tor steel reinforcement fibers. International Conference on Recent Trends in Engineering and Material Sciences (ICEMS-2016). Materials Today: Proceedings. 2017; 4: 9705-9708.

[8] Eisa AS, Elshazli MT, Nawar MT. Experimental investigation on the effect of using crumb rubber and steel fibers on the structural behavior of reinforced concrete beams. Construction and Building Materials. 2020; 252:119078.

[9] Shahjalal M, Islam K, Rahman J, Ahmed KS, Karim MR, Billah AHMM. Flexural response of fiber reinforced concrete beams with waste tires rubber and recycled aggregate. Journal of Cleaner Production. 2021; 278:123842.

[10] Li J. Evaluation of flexural capacity and ductility on high-strength concrete beams reinforced with FRP rebar and steel fiber. The Civil Engineering Journal. 2018; 3:380-393.

[11] Hsie M, Tu C, Song PS. Mechanical properties of polypropylene hybrid fiber-reinforced concrete. Materials Science and Engineering. 2008; 494:153-157.

[12] Poongodi K, Murthi P. Impact strength enhancement of banana fibre reinforced lightweight self-compacting concrete. Materials Today: Proceedings. 2020. doi.org/10.1016/j.matpr.2020.02.108.

[13] Emon MAB, Manzur T, Sharif MS. Suitability of locally manufactured galvanized iron (GI) wire fiber as reinforcing fiber in brick chip concrete. Case Studies in Construction Materials. 2017; 7: 217-227.

[14] Palanisamy M, Kolandasamy P, Awoyera P, Gobinath R, Muthusamy S, Krishnasamy TR, Viloria A. Permeability properties of lightweight self-consolidating concrete made with coconut shell aggregate. 2020; 9(3):3547-3557.

[15] Li S, Zhang Y, Chen W. Bending performance of unbounded prestressed basalt fiber recycled concrete Beams. Engineering Structures. 2020; 221(3):110937.

[16] Taha A, Sayed E, Shaheen YBI. Flexural performance of recycled wheat straw ash-based geopolymer RC beams and containing recycled steel fiber. Structures. 2020; 28:1713-1728.

[17] Adnan HM, Dawood AO. Strength behavior of reinforced concrete beam using re-cycle of PET wastes as synthetic fibers. Case Studies in Construction Materials. 2020;13:e00367.

[18] Alrekabi S, Cundy AB, Lampropoulos A, Whitby RLD, Savina I. Mechanical performance of novel cementbased composites prepared with nano-fibres, and hybrid nano- and micro- fibres. Composite Structures. 2017;178:145-156.

[19] Danso H, Manu D. Influence of coconut fibres and lime on the properties of soil-cement mortar. Case Studies in Construction Materials. 2020;12:e00316.

[20] Danso H. Properties of coconut, oil palm and bagasse fibres: As potential building materials. 3rd International Conference on Natural Fibers: Advanced Materials for a Greener World, ICNF 2017. 21-23 June 2017, Braga, Portugal. Procedia Engineering. 2017; 200:1-9.

[21] ASTM C33/C33M-18, Standard Specification for Concrete Aggregates. 2018; ASTM International, West Conshohocken, PA.

[22] ACI 544.3R-93, Guide for Specifying, Proportioning, Mixing, Placing, and Finishing Steel Fiber Reinforced Concrete. 1998; American Concrete Institute.

[23] ASTM-A 820/A 820 M, Standard Specification for Steel Fibers for Fiber-Reinforced Concrete. 2018; ASTM International, West Conshohocken, PA.

[24] ASTM C1602/C1602M-18, Standard Specification for Mixing Water Used in the Production of Hydraulic Cement Concrete. 2018; ASTM International, West Conshohocken, PA.

[25] Topcu IB, Canbaz M. Effect of different fibers on the mechanical properties of concrete containing fly ash. Constr. Build. Mater. 2007; 21(7):1486-1491.

[26] ASTM C192/C192M-19 Standard Practice for Making and Curing Concrete Test Specimens in the Laboratory 2019. ASTM International, West Conshohocken, PA.

[27] ASTM C143/C143M-15a, Standard Test Method for Slump of Hydraulic- Cement Concrete. 2015; ASTM International, West Conshohocken, PA.

[28] ASTM C293/C293M - 16, Standard Test Method for Flexural Strength of Concrete (Using Simple Beam with Center-Point Loading). 2016; ASTM International, West Conshohocken, PA.

(C) 2021 by the author(s). This work is licensed under a Creative Commons Attribution 4.0 International License (http://creativecommons.org/licenses/by/4.0/).Authors retain copyright of their work, with first publication rights granted to Tech Reviews Ltd. 